\title{
ARQUITETURA DA INFORMAÇÃO PARA UMA ECONOMIA DA INFORMAÇÃO
}

\author{
ARQUITECTURA DE INFORMACIÓN PARA UNA \\ ECONOMIA DE INFORMACIÓN
}

\author{
Mac Amaral Cartaxo* \\ Flávio Augusto Corrêa Basílio** \\ Claudio Gottschalg Duque***
}

\begin{abstract}
RESUMO:
Introdução: A informação é entendida como a matéria-prima básica, da qual dependem os processos sejam para decisão ou aprendizado no âmbito organizacional. Deste modo a informação ao invés de constituir um pressuposto primário sobre a economia é, na verdade, mais do que isso, na medida em que ela é desejada como qualquer outro bem pelos agentes econômicos. Objetivo: $O$ objetivo deste estudo foi identificar indícios da natureza conceitual sobre a heterogeneidade de informação como um fenômeno importante que produz impactos significativos sobre o equilíbrio de mercado e sobre o bem-estar dos agentes econômicos. Metodologia: A pesquisa caracteriza-se como revisão de literatura nos campos da Ciência da Informação, especificamente no que tange a Arquitetura da Informação, contrastando com a Economia visando estabelecer um paralelo a respeito da chamada economia da informação. Resultados: Os principais resultados indicam que possuir uma Arquitetura da Informação que viabilize a ostensividade da informação, possibilita o fácil acesso ao conhecimento buscado por quem demanda, seja em função de sua clareza, conectividade, conteúdo contextualizado ao nível de conhecimento dos usuários, permitindo às organizações maximizar a eficiência das decisões. Conclusão: No que diz respeito ao uso de uma Arquitetura da Informação no âmbito de uma economia da informação, percebe-se que os consumidores aumentam o nível de utilidade na medida em que a informação traduzida de forma barata, clara e acessível em conhecimento reduz o grau de dispersão e de volatilidade dos preços.
\end{abstract}

Palavras-chave: Arquitetura da Informação. Economia. Busca pela Informação. Classificação. Vantagem Competitiva.

*Doutorando em Ciência da Informação do Programa de Pós-Graduação em Ciência da Informação da Universidade de Brasília (UNB). E-mail maccartaxo@gmail.com

** Doutor em Economia pela Universidade de Brasília (UNB). E-mail flaviobasilio@gmail.com

***Doutor em Produção e Gestão da Informação do Programa de Pós-Graduação em Ciência da Informação da Universidade Federal de Minas Gerais (UFMG). Professor do Programa de Pós-Graduação em Ciência da Informação da Universidade de Brasília (UNB). E-mail klauss@unb.br

Inf. Inf., Londrina, v. 22, n. 1, p. $34-59$, jan./abr., 2017. http:www.uel.br/revistas/informacao/ 


\section{INTRODUÇÃO}

Conhecimento é poder! Tendo em vista esta importante frase, falada e defendida por inúmeros pesquisadores, intelectuais e operadores de mercado, as empresas e os governos deveriam sempre se preocupar com mecanismos para adotar o padrão tecnológico em estado da arte e deveriam buscar alternativas para minimizar as assimetrias de informações existentes entre os agentes econômicos.

A teoria econômica tradicional, ancorada nos pressupostos de racionalidade e completude dos mercados, estabelece que os preços deveriam refletir os fundamentos da economia, de modo que o excesso de demanda por bens e serviços deveria ser função apenas dos preços relativos, e não do nível absoluto de preços. Além disso, associados aos dois Teoremas da Teoria do Bem Estar, a alocação no equilíbrio deveria ser Pareto ótima se as hipóteses do equilíbrio competitivo fossem alcançadas. Além disso, a teoria tradicional pressupõe que os agentes compartilham do mesmo nível de informação.

O problema é que a dispersão de informação é fato cotidiano na vida das pessoas. São inúmeros os fatores que explicam esse fenômeno, como informações assimétricas, existência de custos de transações e de logística, dentre outros, que geram atritos às operações de arbitragem. Com efeito, são inúmeros os problemas econômicos relacionados à ideia de mercados eficientes e maiores ainda os problemas relacionados às assimetrias de informações. Ao menos que os mercados fossem completamente centralizados, seria impossível para o agente conhecer todas as variações de preços existentes na economia, mesmo considerando apenas os bens homogêneos.

Desta forma, ao contrário do modelo competitivo dos livros textos em que em equilíbrio haveria apenas um único preço, a realidade dos estudos empíricos mostra que a dispersão de preços constitui a regra e não à exceção das economias de mercado. De fato, segundo Varian (1980) os preços pagos pelo consumidor, para um mesmo bem, costumam variar mais de $30 \%$, razão pela qual a lei do preço único dos livros não é, de forma alguma uma lei. 
Do ponto de vista prático, as empresas possuem departamentos específicos de compras que possuem como tarefa pesquisar, nos diversos fornecedores, a relação dos preços dos produtos. Da mesma forma que vendedores habilidosos conseguem extrair o maior preço dos consumidores, como ocorre com o vendedor de tapetes marroquinos, habilidosos compradores conseguem economizar preciosos recursos para as empresas.

Nesse sentido, a informação, ou em sentido mais estrito, o conhecimento sempre foi um ativo valioso para aqueles que o possuem. $\mathrm{Na}$ sociedade portuguesa medieval, a pesca era tão importante para a comunidade, não apenas pelos inúmeros fatores econômicos, mas também do ponto de vista alimentar, que o local onde os peixes eram capturados deveria ser compartilhado com a comunidade para assegurar o contínuo fluxo do suprimento do pescado. Contudo, com o surgimento da concorrência com outras nações, as Cortes passaram a conferir privilégios e adotaram medidas de proteção do pescado. Hoje, mesmo com barcos equipados com sonares capazes de mapear via satélite a movimentação dos cardumes, o pescador guarda com meticuloso segredo o armazenando das informações de longitude e latitude das áreas de pesca e se recusa a compartilhar essas informações com os demais pescadores.

Assim, a informação ao invés de constituir um pressuposto primário sobre a economia é, na verdade, mais do que isso, na medida em que ela é desejada como qualquer outro bem pelos agentes econômicos. Nesse sentido, a informação ganha um papel duplo na teoria econômica. De um lado ela é a plataforma que possibilita aos consumidores e produtores formarem expectativas ou premissas sobre os preços relativos dos bens e serviços. De outro, a informação constitui um importante ativo que agrega valor e utilidade ao seu detentor.

Contudo, determinar o valor da informação não é, de forma alguma, tarefa trivial. Segundo o artigo seminal de Arrow (1962) o valor da informação não pode ser completamente determinado até que o seu conteúdo seja colocado em uso. Em perspectiva mais recente, o também laureado com o prêmio Nobel de economia George Stigler estabelece que o valor da 
informação advém do seu uso e, portanto, o problema relacionado à incerteza do valor da informação seria resolvido pela teoria da expectativa do valor, calculada pela média de possíveis valores atribuídos à informação ponderado pelas respectivas probabilidades.

Assim, em termos formais, o valor da informação pode ser expresso por:

$$
\text { Valor da Informação } x=E[u s o(x)]
$$

A grande vantagem de se expressar o valor da informação na forma sugerida pela equação (1) é que, agora, a informação pode ser analisada como um bem de valor fixo. Por sua vez, o grau de variabilidade ou de incerteza também passa a ser contemplado pela expressão acima.

Com efeito, o valor da informação ao ser expresso sob o enfoque das expectativas racionais assume que os agentes podem falhar nas suas previsões sobre os preços, mas não de forma sistemática. Assim, ao invés dos agentes serem sistematicamente "tolos" na formação de suas expectativas, eles deveriam levar em consideração todas as informações relevantes disponíveis para, assim, maximizarem o seu bem estar e promovem, de forma instantânea, o equilíbrio em todos os mercados a partir do vetor ótimo de preços. Desta forma, sob expectativas racionais qualquer possível excesso de demanda seria instantaneamente eliminado [Lucas (1973, 1975, 1976 e 1977) e Sargent e Wallace $(1975,1976)]$.Como Lucas $(1977$, p. 15) observa: "even psychotic behavior can be (and today, is) understood as "rational" given a sufficiently abnormal view of relevant probabilities".

Mas, adotado o expediente de precificar a informação com base na teoria das expectativas racionais, como seria possível explicar os desvios da economia em relação ao produto de equilíbrio? Ou ao fato dos agentes tomarem decisões equivocadas baseadas nos preços dos produtos? Ou ainda, como os agentes podem pagar preços distintos por preços idênticos?

Um caso típico para responder essas questões diz respeito ao comportamento do consumidor na busca pelo menor preço para um produto qualquer. Certamente, ele quer pagar o menor valor possível pelo bem. Ocorre que todas as informações sobre o preço do produto não estão disponíveis, 
sendo possível que o consumidor encontre estabelecimentos com preços distintos para produtos estritamente homogêneos.

Na busca pelo menor preço, o consumidor só gastará tempo e esforço se o benefício auferido superar os custos relacionados à busca. Como consequência, o agente racional não precisa comprar o produto com o menor preço de mercado, porque as decisões dos consumidores dependem de quão custoso é a busca pela informação (search cost). Se dentro do processo de busca o consumidor encontrar um preço entendido como razoável, então a relação entre custo e benefício de se manter o processo de busca pelo menor preço é baixa. Por outro lado, se o preço encontrado for elevado, o consumidor, de forma racional, irá avaliar o benefício em se manter o processo de busca pelo menor preço.

Um processo mapeado descreve um conjunto de signos que apresentam as etapas, atividades, atores, contexto e condições inerentes ao andamento de um processo. Sabe-se que preocupar-se com os signos, com o processo de significar, é preocupar-se com o processo de representar um objeto não necessariamente presente, para sobre ele refletir (comunicação interna) ou para referir-se a ele para outra pessoa (comunicação interpessoal). Pode-se então entender que o processo de significação está na base do pensamento, quando refletimos sobre o mundo e seus eventos, e da troca de informações, na comunicação que torna ideias, afetos e comportamentos comuns.

\section{MODELO DE BUSCA PELA INFORMAÇÃO}

A importância da heterogeneidade de informação é um fenômeno importante que produz impactos significativos sobre o equilíbrio de mercado e sobre o bem-estar dos agentes econômicos. Em seu artigo seminal, Stigler (1961) aborda esse amplo problema identificando o efeito da dispersão sobre as decisões dos agentes. De forma geral, pode-se imaginar que, dentro de certos parâmetros, que o preço praticado por uma mercadoria possui comportamento análogo ao de uma variável aleatória para a qual os agentes conhecem a distribuição de probabilidade. Ou seja, mesmo sem saber o real 
valor da variável, os agentes conhecem a média e variância associadas ao preço.

Stigler (1961) pressupõe que o comprador decide, antes mesmo de iniciar a sua pesquisa de preços, quantos vendedores serão consultados sobre o preço de determinado bem. Desta forma, uma vez tomada a decisão do tamanho da amostra de preços, o comportamento do comprador não varia no decorrer da pesquisa, pelo que o autor denomina esta estratégia por amostra de tamanho fixo. Assim, se imaginar um sorteio em que dez números são colocados em um chapéu, o valor esperado do menor número encontrado em uma amostra de tamanho ${ }^{N}$ tem que ser menor do que o menor valor esperado para uma amostra de tamanho $N-1$. Com efeito, quanto maior o tamanho da amostra, menor será o valor esperado do preço.

Em termos formais, a busca pelo menor preço é escrita como uma função de distribuição de probabilidade, em que os preços são extraídos de forma independente.

Assim, tomando uma amostra com $n$ observações, a função de distribuição de probabilidade será tal que:

$$
F(p \mid n)=1-[1-F(p)]^{\mathrm{n}}
$$

Contudo, é importante salientar que à medida que a busca por preços mais baixos prossegue, menor será a probabilidade de se encontrar um preço ainda menor do que os que já estão disponíveis ao pesquisador. Isso significa que a redução marginal esperada pelos preços apresenta benefício marginal decrescente. Por outro lado, como o comprador irá, de forma racional, sempre escolher sempre o menor preço dentre os preços consultados, por outro lado, o processo de busca por preços mais baixos gera custo de procura ao pesquisador, que em alguns casos pode envolver aquisições de informações, contratação de trabalhadores para efetuar buscas mais precisas ou até mesmo aquisição de bancos de dados, etc.

Assim, o benefício do consumidor será igual a soma do preço mínimo com ao custo incorrido pela busca pelo menor preço. Definindo a função de 
benefício do consumidor por, o valor esperado do processo de busca por menor preço pelo consumidor será tal que:

$$
E(n)=E\left[P_{\min }-s\right]
$$

Em que: $P_{\min }$ é o preço mínimo encontrado es a função de custo associada ao processo de busca por preços.

Supondo que o consumidor possui uma função utilidade esperada sobre dois bens quaisquer, $x$ ey. Para demonstrar o impacto da busca por informações sobre a decisão do consumidor, supõe-se, por simplicidade, que o preço do bem $y$ é conhecido com certeza e o preço do bem $x$ segue uma função de distribuição de probabilidade com média e variância conhecidas. O consumidor deseja maximizar o seu consumo sobre os bens $x$ e $y$ e possui função utilidade sobre os dois bens do tipo Cobb-Douglas. Com efeito, o problema do consumidor será maximizar:

$$
\begin{aligned}
& \max E[u]=E\left[x^{\gamma} y^{1-\gamma}\right] \\
& y \in(0,1) \\
& \text { s. a. } p_{x}(s) x+p_{y} y \leq w
\end{aligned}
$$

Em que: $p_{x}$ é o preço esperado do bem $x, p_{y}$ é o preço do bem $y, x$ é a quantidade demandada do bem $x, y$ é a quantidade demandada do bem $y$, we é a riqueza do consumidor. Resolvendo-se o problema do consumidor a partir das condições de primeira ordem do problema (4), encontram-se as seguintes demandas ótimas:

$$
\begin{aligned}
& x^{*}=\gamma \frac{w}{p_{i}(\theta)} \\
& y^{*}=(1-\gamma) \frac{w}{r_{y}}
\end{aligned}
$$

Substituindo-se (5), (6) e (3) em (4), encontra-se:

$$
E[u]=E\left\{\left[\frac{w-s}{\gamma p_{x}(s)}\right]^{\gamma}\left[\frac{w-s}{(1-\gamma) p_{y}}\right]^{\gamma}\right\}
$$

Considerando as propriedades da utilidade esperada e, supondo, por simplicidade e sem perda de generalidade que $\gamma=0,5$, ou seja, que o consumidor consome a mesma quantidade dos dois bens, segue-se que a utilidade esperada do consumidor será tal que: 


$$
E[u]=\frac{1}{2}(w-s)\left(P_{x}(s) P_{y}\right)^{-u b}
$$

A partir da equação (8), é possível encontrar a utilidade do consumidor relacionada ao processo de busca pelo menor preço. Diferenciando-se (8) em relação as, obtém-se:

$$
-\frac{1}{2}\left(P_{x} P_{y}\right)^{-u b}-\frac{1}{4}(w-s)\left(P_{x}(s) P_{y}\right)^{-1 b} \frac{\partial p_{x}}{\partial s}=0
$$

De acordo com a equação (9), o membro direito da expressão anterior pode ser lido como o beneficio marginal da pesquisa enquanto que o membro esquerdo representa o custo marginal da pesquisa. Assim, o custo marginal (subjetivo - devido à esperança matemática) do processo de busca reduz a quantidade consumida dos dois bens por parte do consumidor, ao passo que o benefício marginal (esperado) da busca reduz o preço pago pelo bem $x$. Considerando as duas dimensões entre custo e benefício esperado, nada se pode afirmar sobre o benefício do consumidor em manter o processo de pesquisa do menor preço sem que se saiba a taxa na qual o preço cai à medida que mais preços são consultados.

Desta forma, verifica-se que o comportamento dos consumidores depende apenas do custo marginal da pesquisa e da função de distribuição dos preços na economia. Na decisão de pesquisa, o consumidor diminuição o esforço empregado na pesquisa se o custo marginal da pesquisa aumentar, ou o contrário, se o custo reduzir.

Seguindo Stigler (1961) e supondo que a dispersão de preços segue, por simplicidade de cálculo, uma distribuição uniforme com intervalor contido no espaço amostral definido sobre $\lceil a, b]$, então as estatísticas descritivas relacionadas ao preço possuem as seguintes propriedades:

Média:

$$
E\left[p_{x}\right]=\int_{-\infty}^{\infty} p_{x} f\left(p_{x}\right) d p_{x}=\int_{a}^{b} \frac{1}{b-a} d p_{x}=\frac{1}{b-a}\left[\left(p_{x}\right)^{2}\right]_{a}^{b}=\frac{a+b}{2}
$$

Variância:

$E\left[\left(p_{x}\right)^{2}\right]=\sigma^{2}=\int_{-\infty}^{\infty}\left(p_{x}\right)^{2} f\left(p_{x}\right) d p_{x}=\int_{m}^{b}\left(p_{x}\right)^{2} \frac{1}{b a} d p_{x}=\frac{1}{b a}\left[\frac{\left(p_{x}\right)^{5}}{3}\right]_{a}^{b}=\frac{(b-a)^{2}}{12}$

Considerando-se que uma variável aleatória representa o análogo contínuo dos resultados igualmente prováveis, no sentido de que para qualquer intervalor $[a, c]$, em que $a \leq c<d \leq b$ é a mesma para todos os subintervalos 
que tenham o mesmo comprimento. Sendo assim a função densidade de probabilidade será tal que:

$$
P\left(c \leq p_{x} \leq d\right)=\int_{\varepsilon}^{d} f\left(p_{x}\right) d p_{x}=\frac{d-\varepsilon}{b-a}
$$

Sendo que: $\int_{-\infty}^{\infty} f\left(p_{x}\right) d p_{x}=1$

Tendo em vista o processo de busca pelo menor preço por parte do consumidor, o menor preço encontrado após $n$ buscas será dado por:

$$
\operatorname{Prob}\left[p_{x}=p_{x-\text { minimo }}\right]_{n}=\operatorname{prob}\left(z>p_{x}\right)^{n}, z>0
$$

Sendo assim, a função densidade de probabilidade dos preços de após $n$ tentativas será tal que:

$$
\mu\left(z>p_{x}\right)=\int_{p_{x} b-a}^{b} \frac{1}{b p_{x}}=\frac{h-p_{x}}{b-a}
$$

Substituindo-se (12a) em (13), encontra-se:

$$
\text { Prob }\left[p_{x}=p_{x-\operatorname{minimo}}\right]_{n}=\left[\frac{b-p_{x}}{b-a}\right]^{n}
$$

Da equação (14), obtém-se a função cumulativa de probabilidade, a qual é descrita por:

$$
F\left(p_{x}\right)=1-\left[\frac{b-p_{x}}{b-\alpha}\right]^{n}
$$

Para calcular o menor preço que o consumidor irá encontrar após $n$ buscas, diferencia-se a equação (15) em relação ao preço do bem $x$, de tal sorte que:

$$
\rho\left(p_{x}\right)=\frac{\partial F\left(p_{x}\right)}{\partial p_{x}}=n-\frac{\left(b-p_{x}\right)^{n-1}}{(b-a)^{n}}
$$

Calculando-se o menor preço esperado após $n$ buscas, obtém-se da equação (16) a seguinte expressão':

$$
E\left[p_{x}\right]=\int_{a}^{b} p_{x} \rho\left(p_{x}\right) d p_{x}=a+\frac{b-a}{n+1}
$$

A partir da equação (17), que descreve o preço esperado médio do produto, depende do número de buscas realizadas. Com efeito, quanto maior o número de buscas, menor o preço, que se aproxima assintoticamente do limite inferior do intervalo, estabelecido pelo parâmetro $a$, quando $n \rightarrow \infty$. Desta

\footnotetext{
${ }^{1} \mathrm{~A}$ integral deve ser resolvida por partes.
} 
forma, fica evidente que o consumidor desfruta de ganhos à medida que ele intensifica a busca pelo menor preço. Não por acaso, a compra de automóveis, imóveis e bens com elevado impacto no orçamento do consumidor são aqueles que envolvem grande número de buscas.

Contudo, como existem custos relacionados a busca pelo menor preço, o consumidor se defrontará com um dilema entre intensificar sua procure pelo menor preço e incorrer em custos adicionais ou encerrar o trabalho de pesquisa. Do ponto de vista racional, o número ótimo de buscas será aquele em que o benefício marginal iguala o custo marginal. $O$ benefício do consumidor em se fazer buscas pode ser obtido a partir da equação (17). Desta forma, obtém-se:

$$
B=-q \frac{\partial E\left|p_{x}\right|}{\partial_{n}}
$$

Em que: $B$ é o benefício auferido pelo consumidor em se fazer buscas e $q$ é o peso do produto $x$ no orçamento do consumidor.

Diferenciando-se (17) em relação an e substituindo o resultado em (18), tem-se:

$$
n=\left[\frac{q(b-a)}{B}\right]^{1 / 2}-1
$$

A equação (19) explicita o número ótimo de buscas em relação ao menor preço. Substituindo-se (11) - equação da variância, em que $(b-a)=\sqrt{12} \sigma$, em (18), encontra-se $\mathrm{e}^{2} \quad n=1,86\left[\frac{\sigma q}{\bar{z}}\right]^{\frac{2}{2}}-1$

Tomando-se da equação (5) o peso do bem $x$ no orçamento do consumidor e, na sequência substituindo-se o valor em (20), encontra-se:

$$
n=1,86\left[\frac{y_{x}}{\gamma} \frac{y}{z}\right]^{\frac{2}{2}}-1
$$

A partir da equação (21) é possível observar que o número ótimo de buscas é afetado positivamente pelo desvio-padrão da distribuição de preços e pelo peso do produto no orçamento do consumidor. Em outro prisma, os bens

\footnotetext{
$212^{1 / 4} \approx 1,86$
} 
que o consumidor já estabeleceu certos hábitos de compras tendem a apresentar menores dispersões de preços do que aqueles que fazem parte esporadicamente da cesta de aquisições.

Desta forma, verifica-se que o comportamento do consumidor depende do custo marginal da pesquisa, da função de distribuição dos preços na economia e do peso do bem pesquisado em seu orçamento.

$\mathrm{Na}$ decisão de pesquisa, o consumidor diminui o esforço empregado na pesquisa se o custo marginal aumentar. Caso contrário, ele aumenta o seu esforço na busca pelo menor preço. Assim, de forma geral, quanto menor o custo da informação para o consumidor, menor será o valor esperado do preço do produto adquirido.

Com efeito, a informação constitui uma importante plataforma que permite com que haja convergência entre as decisões dos consumidores em direção ao menor preço de mercado. Sendo assim, quanto maior a disponibilidade clara e barata de informação ao consumidor, maior será a tendência de queda do preço no mercado.

\section{FONTES ADICIONAIS DA DISPERSÃO DE PREÇOS}

$\mathrm{Na}$ seção anterior, verificou-se que a dispersão de preços pode ocorrer mesmo em um simples modelo matemático, com um único consumidor e com função utilidade convencional, com todas as suas propriedades de homogeneidade. Verificou-se que quanto maior o peso do bem no orçamento do consumidor, maior o incentivo à busca pelo menor preço e, portanto, menor a dispersão esperada dos preços e que a própria dispersão dos preços influencia na quantidade ótima de pesquisas que o consumidor fará para procurar o menor preço. Contudo, o mundo real é ainda mais complexo do que o estabelecido pelo modelo teórico. Existem outras variáveis que podem influenciar na dispersão dos preços.

Assim, uma importante fonte adicional de dispersão dos preços decorre das informações disponíveis, ex-ante, para o consumidor. Ao se imaginar, por exemplo, que os consumidores são heterogêneos, pode-se inferir que aqueles com maior grau de escolaridade dispõem de mecanismos mais eficientes de 
busca pela informação. Assim, quanto maior a educação, menor seria a dispersão esperada dos preços.

Da mesma forma, quanto maior o acesso à informação, com o uso de tecnologias digitais, por exemplo, menor seria a dispersão esperada de preços. Ou ainda, quanto maior for o consumo de massa do bem, menor a tendência de dispersão acentuada dos preços, pelo mesmo motivo relacionado aos hábitos de compras dos consumidores em relação a compras casuais de bens e serviços.

Além disso, tendo em vista que experiências heterogêneas levam a diferentes estruturas de custos relacionada a busca pela informação, espera-se que quanto maior a rede de network do consumidor, menor tende a ser o sacrifício incorrido na busca pelo melhor emprego e por maior salário.

Do ponto de vista macroeconômico, a inflação também constitui uma importante fonte amplificadora da dispersão de preços, pois ao se considerar que as firmas não reprecificam os preços uniformemente (Stiglitz, 1979), o processo inflacionário tende a elevar a variância da dispersão dos preços, levando ao aumento do custo de busca por parte dos consumidores e, portanto, à redução de bem-estar.

Deste razoado, pode-se afirmar que a dispersão de preços é altamente influenciada pela presença diferenciada de consumidores informados e também pela estabilidade macroeconômica do país. Após essa breve reflexão, é digno de nota que, reconhecer que a informação é imperfeita e que são inúmeras as fontes de assimetrias existentes na economia que possibilita com que importantes fenômenos econômicos e sociais possam ser explicados.

A dispersão ou volatilidade são, sem dúvida, importantes componentes da incerteza relativa ao comportamento dos preços dos ativos financeiros. Nesse sentido, independente das particularidades teóricas relacionadas à precisão do conceito de incerteza, a teoria econômica é unânime em enfatizar os efeitos danosos que este fenômeno provoca sobre as decisões de investimento em nível macroeconômico.

De um lado, se as flutuações puderem ser previstas adequadamente (expectativas racionais), os agentes anteciparão qualquer custo relacionado à 
variação de preço dos ativos e não haverá nenhuma separação entre a tomada de decisão do agente no presente em relação à decisão futura. Por outro lado, se as condições econômicas estiverem sujeitas a flutuações imprevisíveis, a ignorância ou a precária base de informação relativa ao futuro prevalecerá, de maneira que as imperfeições dos ajustamentos recairão sobre as decisões de investimento, uma vez que os agentes se protegerão contra as flutuações adversas da forma mais simples possível: reduzindo o risco dos portfólios na forma do aumento da demanda por moeda. Todavia, as consequências práticas de ocorrer uma variação adversa de preços prevista, ou de modificação não prevista que leve ao aumento da incerteza, é a contração dos planos de investimentos dos agentes, ocasionando retração da demanda agregada e queda do potencial de crescimento da economia.

Neste sentido, a variabilidade ou variância dos dados, embora adimensional, pode ser utilizada como medida comparável a partir de uma escala de ordenação. A racionalidade deste resultado é baseada na ideia de que quanto maior for a variabilidade do sistema de crença (ou de confiança) do agente, mais flexível será sua escolha. Assim, o efeito da volatilidade ou dos distúrbios sobre os investimentos pode ser explicitado da seguinte forma:

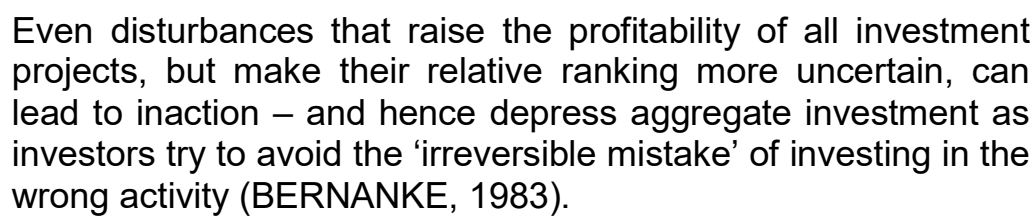

Levando essa discussão para o plano das complexas relações externas que as economias possuem, tais como os compromissos da dívida externa, as relações comerciais e financeiras, os incentivos para a entrada de investimento externo direto, as relações de arbitragem entre os diversos ativos financeiros, etc., observa-se que a informação constitui a plataforma de interação entre os agentes. Sendo assim, quanto melhor for 0 arranjo estabelecido para a divulgação da informação ou quanto melhor for o paradigma relacionado à Arquitetura da Informação (Al), menor será a volatilidade e, portanto, menor será o impacto no bem-estar dos agentes econômicos. 
No final do século XIX, eram poucos os estudos e as discussões relacionadas a esse tema. Mesmo considerando que os precursores, como Smith, Mill e Marshall reconhecessem a importância da informação em seus textos, esse tema nunca guardava posição central, de destaque na análise. Agora, no século XXI, a teoria da economia da informação abre espaço para uma rica agenda de pesquisa para os próximos anos. Assim, questões relacionadas ao processamento de informações, à estrutura das organizações e à forma como a sociedade absorve, trata, transmite e aprende com as informações será cada vez mais, uma rica agenda de pesquisas. Neste aspecto, as questões relevantes serão colocadas em perspectiva dinâmica, muito além do escopo desenvolvido neste trabalho.

\section{A ARQUITETURA DA INFORMAÇÃO E SUA CONTRIBUIÇÃO PARA ECONOMIA DA INFORMAÇÃO}

Em função do exposto até o momento, fica patente que a sociedade caminhou para incorporar de maneira consistente um paradigma caracterizado por organizações que incorporam conhecimentos visando a obtenção da sua identidade e the conduzirem ao sucesso e à sustentabilidade. Esses conhecimentos constituem a essência do negócio e são críticos para a sobrevivência da organização. Tais conhecimentos necessitam ser identificados, preservados e alavancados pelas lideranças organizacionais. Entretanto, falta uma abordagem geral integrada nessa área estratégica e as organizações necessitam gerir mais eficazmente o conhecimento como fonte mais relevante de vantagem competitiva (TURNE; MINONNE, 2010).

O surgimento de uma economia baseada em informação ou no conhecimento é indiscutível, porém poucas organizações demonstram ter integrado de forma significativa esse conhecimento a suas estratégias. Para essa incoerência, existem várias explicações, dentre elas, a de que tirar proveito das possibilidades estratégicas da informação aperfeiçoada é extremamente difícil devido, principalmente, ao seu grande volume e heterogeneidade. 
Neste sentido, Takeuchi e Nonaka (2008) são enfáticos em caracterizar como a principal razão do sucesso das organizações, na sua competência na construção do conhecimento organizacional. Os autores afirmam:

O que as empresas em movimento necessitam é de um novo paradigma de administração, baseado na criação do conhecimento. Ele é mais bem equipado para lidar com as turbulências, as incertezas, as inconsistências, as contradições e os paradoxos (NONAKA; TAKEUCHI, 2008, p.37).

Assim, o grande desafio percebido por diversos autores é a forma de se traduzir e representar este conhecimento existente de forma que seja acessível a todos os colaboradores da organização (Choo, 2006; Polanyi, 1997; Biggiero, 2007; Blacker, 1995; Nonaka e Konno,1998; e Takeuchi e Nonaka ;2008).

Nesta ótica Choo afirma que:

[...] a construção do conhecimento é conseguida quando se reconhece o relacionamento sinérgico entre o conhecimento tácito e o conhecimento explícito dentro de uma organização, e quando são elaborados processos sociais capazes de criar novos conhecimentos por meio da conversão do conhecimento tácito em conhecimento explícito. (CHOO, 2006, p.36).

Nesse contexto a Arquitetura da Informação (Al) se apresenta com um conceito que pode ser entendido como um framework para a representação, organização e armazenagem da informação em repositórios providos de consistência, compartilhamento, documentação, privacidade e recuperação eficaz de seus conteúdos.

Sob o ponto de vista organizacional, Brancheau e Wetherbe afirmam que Arquitetura da Informação consiste em um plano para modelagem dos requisitos informacionais de uma organização. Esse plano provê um modo de mapear as informações necessárias à organização, relativas aos processos do negócio e documentar seus inter-relacionamentos (Brancheau e Wetherbe, 1986).

Na visão de Davenport (1998), a Al simplesmente constitui-se de uma série de ferramentas que adaptam os recursos às necessidades da informação. Um projeto bem implementado estrutura os dados em formatos, categorias e relações específicas. A arquitetura faz a ponte entre o comportamento, os 
processos e o pessoal especializado e outros aspectos da empresa, como métodos administrativos, estrutura organizacional e espaço físico.

Seguindo esse enfoque, Rosenfeld e Morville (2002) propõem o modelo ilustrado na figura 1, para representar a Arquitetura da Informação. A Al é representada como a interseção de contexto, conteúdo e usuários. Para que o espaço informacional de uma organização seja bem projetado, há necessidade de se conhecer os objetivos do negócio da organização (contexto), estar consciente da natureza e volume de informações existentes e sua taxa de crescimento (conteúdo) e de se entender as necessidades e os processos de busca do público-alvo (usuários).

Figura 1 - Modelo de Arquitetura da Informação.

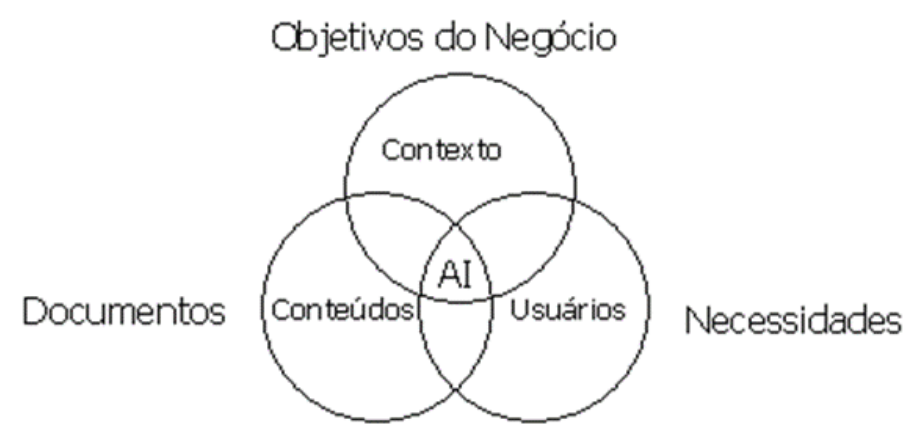

Fonte: (Rosenfeld; Morville, 2002)

A informação é entendida como a matéria-prima básica, da qual dependem os processos sejam para decisão ou aprendizado no âmbito organizacional. Assim, quanto mais importante for certa informação para as necessidades da organização, e quanto mais rápido for o acesso a ela, com maior eficácia as organizações poderão atingir os seus objetivos. Levy (1997) corrobora com esse pensamento, apontando que a informação e o conhecimento são as principais fontes de riqueza, e McGee e Prusak (1994) mencionam que, na Sociedade da Informação, o sucesso é determinado pelo saber, e não, somente pelo que se possui.

A arquitetura da informação, em última análise, tem como mister se ater com a identificação das necessidades de informações, com a compreensão dos conteúdos e dos desafios de organizá-las de maneira a torná-las úteis com 
a oportunidade necessária. Quando descrita e disposta em concordância com os usuários da informação, essa arquitetura possibilita que as parte interessada na tomada de decisão utilizem a informação e falem a mesma língua (McGEE e Prusak, 1994). Estes autores sinalizam que a interação entre a informação com a arquitetura agrega valor, na medida em que torna a estrutura e os relacionamentos mais explícitos.

Já a clássica a proposta de Urdenata (1992) identifica quatro classes diferentes de informação: dados, informação, conhecimento e inteligência. Dados são sinais que não foram processados, correlacionados, integrados, avaliados ou interpretados de qualquer forma, ou seja, se caracteriza como matéria-prima a ser utilizada na produção da informação. Já a informação consiste dos dados processados para serem exibidos em uma forma inteligível às pessoas que vão utilizá-los, pois se encontra vinculado ou integrado a outra informação previamente existente na organização. O conhecimento pode ser definido como sendo informações que foram analisadas e avaliadas sobre a sua confiabilidade, sua relevância e sua importância, ou seja, já receberam um juízo de valor no âmbito da organização, o conhecimento não é estático, modificando-se mediante interação com o ambiente. Inteligência pode ser entendida como sendo o conhecimento contextualmente relevante que permite atuar com vantagens no ambiente considerado.

Figura 2 - Classificação da Informação 


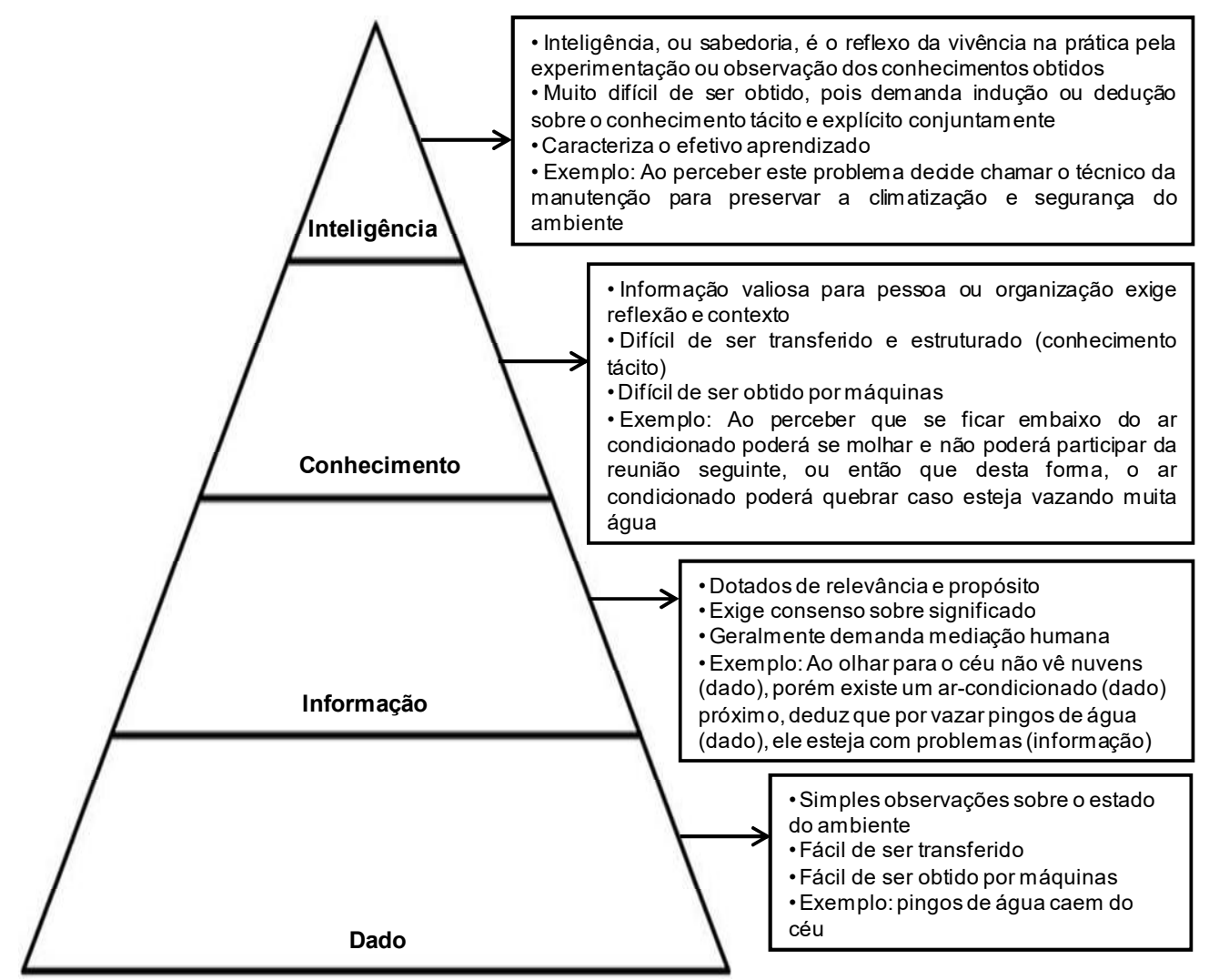

Fonte: Adaptado de Urdaneta (1992)

Em função do exposto, para fins desta pesquisa, a definição de informação encontrada em McGee e colaboradores torna-se indicada:

[...] a informação não se limita a dados coletados; na verdade informação são dados coletados, organizados, ordenados, aos quais são atribuídos significados e contexto, ou seja, para que os dados se tornem úteis como informação a uma pessoa encarregada do processo decisório é preciso que sejam apresentados de tal forma que essa pessoa possa relacioná-los e atuar sobre eles.(MCGEE et al,1994, p.23)

Deste modo o valor da informação pela classificação sinalizada por Urdenata(1992) se dá na medida em que mais ela se aproximará do conceito de conhecimento ou inteligência, haja vista ela demandar reflexão e contexto. Com efeito, valendo da afirmação de Stigler (op cit), que estabelece que o valor da informação advenha do seu uso e isto dependerá necessariamente do contexto onde está inserido, para viabilizar uma arquitetura da informação que possibilite o maior valor possível se deve levar em conta o problema já 
mencionado no âmbito da economia, qual seja, à incerteza do valor da informação seria resolvido pela teoria da expectativa do valor, calculada pela média de possíveis valores atribuídos à informação ponderado pelas respectivas probabilidades.

\section{A ARQUITETURA DA INFORMAÇÃO COMO VANTAGEM COMPETITIVA}

O acesso mais rápido ao conhecimento que subsidiará a tomada da decisão e deste modo poderá propiciar um valor competitivo ao consumidor ou produtor é quase senso comum. As organizações têm desenvolvido diversos sistemas que possibilitem integrar e apresentar as informações de maneira rápida e oportuna fornecendo alertas que gerem ações oportunas de aquisição de insumos ou venda de produtos com oportunidade.

Deste modo, pode-se considerar que mais do que dispor do dado ou da informação, se faz mister recuperar, organizar e apresentar as informações ou conhecimentos gerados de modo que os atores envolvidos no processo de intelecção deste conjunto artefatos seja facilitado em seu entendimento ou interpretação, em função da forma como se disponha ou estruture as informações.

É neste momento que a Arquitetura da Informação demonstra seu valor, pois conforme Wurman (2005), a organização é tão importante quanto o conteúdo, nas suas palavras:

Encontrar, filtrar, classificar, organizar e marcar a informação é mais importante do que criá-la. Afinal, que utilidade teria uma biblioteca se todos os livros fossem empilhados ao acaso pelo chão? A forma de organizar e apresentar a informação é tão importante quanto o conteúdo. (WURMAN, 2005, p. 10).

O uso na Arquitetura da Informação de Tecnologia da Informação e ferramentas a ela vinculadas fica patente, pois conforme afirmam Camargo e Vidotti (2006) a arquitetura da informação concentra-se na tentativa de unificar métodos de recuperação, classificação, organização e apresentação da informação, empregando técnicas oriundas da arquitetura tradicional aplicadas 
a ambientes digitais com utilização de ferramentas da tecnologia da informação.

Porém o mais evidente, no que tange ao uso da Arquitetura da Informação está seu uso no âmbito das organizações, destacando, neste aspecto, McGee e Prusak (1994) que a arquitetura da informação deve se preocupar com os seguintes objetivos em contextos organizacionais:

a) Identificar as estratégias, origens, filtros e aproveitamento da informação;

b) Demarcar os limites dos espaços informacionais;

c) Facilitar o acesso à informação;

d) Aperfeiçoar a adaptabilidade estabelecida pelas políticas da informação;

e) Melhorar a comunicação gerencial com a definição dos modelos de informação compartilhada.

Percebe-se que em função destes objetivos em contextos organizacionais que a arquitetura da informação busca a unificação de métodos de recuperação, classificação, organização e apresentação da informação, com a utilização de técnicas oriundas da arquitetura tradicional aplicadas a ambientes digitais com utilização de ferramentas da tecnologia da informação (Camargo e Vidotti, 2006).

Deste modo, a Arquitetura da Informação que busca propiciar vantagem competitiva a consumidores ou produtores deve contemplar:

Conhecimento sobre o usuário da informação: o que significa saber, aspectos oriundos da análise ergonômica do trabalho (idade, gênero, nível de escolaridade, estratégias e métodos de trabalho) também aquelas ligadas as suas competências (conhecimentos, habilidades e atitudes), o que abarca dimensões importantes em termos cognitivos que demandariam inclusive o conhecimento sobre reações emocionais do potencial usuário de uma informação (CHOO, 2006). Disponibilizando informações alinhadas e "customizadas" as características do usuário que as demanda; não adianta se apresentar muitos dados econômicos ou matemáticos a quem não entende.

Contexto: Choo (2006) afirma que as organizações em função das suas crenças e valores sobre o ambiente que as cerca, percebe e interpreta de modo diferente os dados e informações que obtém do ambiente externo, deste modo sua interpretação e compreensão da realidade que gerará o 
conhecimento é diretamente afetado pelo contexto em que se encontram inserido. Do mesmo modo, Morville e Rosenfeld (2006) propõem que o conhecimento e compreensão das necessidades de informação dos usuários num contexto específico, ajudará a definir o posterior comportamento de busca, bem como a melhor forma de representar a linguagem pela qual se pretende obter o melhor entendimento. Por vezes o usuário desta informação pode até possuir competência técnica para digerir dados estatísticos ou econômicos, porém não possui tempo, e deste modo apenas um gráfico ou índice pode ser suficiente para tomada de decisão.

Conteúdo: Choo (op cit) caracteriza que o conteúdo quando descrito permite a sua representação, organização e posterior armazenamento e resgate, deste modo a sua definição de maneira específica é condição básica propiciar a sua estruturação em termos de uma arquitetura lógica que segundo Morville e Rosenfeld (2006) possibilitará a sua coerente classificação e ordenação das informações. A clara definição de parâmetros financeiros deve ser um pressuposto, de modo que a informação contemple o princípio da ostensividade.

Conectividade: A conexão entre conteúdo internos e externos, alinhados num dado contexto, de modo que se propicie informações contemporâneas e coetâneas é uma característica relevante de uma boa arquitetura da informação, pois deste modo se conseguirá obter oportunidade e velocidade na circulação do conhecimento. A oportunidade da informação é um diferencial, pois não adianta apresentar uma variação cambial ou de preço de produto com atraso ou quando não se dispõe mais de tempo para sua compra ou venda.

Clareza: A estrutura navegacional onde estão inseridas as representações das informações deve apoiar de forma consistente os usuários a visualizarem e entenderem onde se encontram e para onde se dirigirem em busca de novos conhecimentos, deste modo, hierarquias desconexas ou padrões inconsistentes devem ser evitados. Neste sentido Nielsen (2007, p. 178) afirma que "quando a navegação muda drasticamente de uma página para outra, as pessoas precisam desviar sua atenção do uso do site para descobrir como utilizá-los". A mesma lógica pode ser utilizada na descrição de documentos, 
diagramas e fluxos com representações de processos, gráficos, índices e valores. Nielsen (op cit) também aborda nesta perspectiva da clareza que o uso excessivo de animações, cores ou diferenciadas representações também ajudam a distrair o usuário que busca ou recebe a informação, sites econômicos ou gerenciais, bem como painéis de bordo de ferramentas de gestão devem primar pela simplicidade e assertividade na apresentação dos dados.

\section{CONSIDERAÇÕES FINAIS}

Ter uma Arquitetura da Informação que viabilize a ostensividade da informação, permitindo o fácil acesso ao conhecimento buscado por quem demanda, seja em função de sua clareza, conectividade, conteúdo contextualizado ao nível de conhecimento dos usuários, permite às organizações maximizar a eficiência das decisões. Também permite aos consumidores aumentar o nível de utilidade na medida em que a informação traduzida de forma barata, clara e acessível em conhecimento reduz o grau de dispersão e de volatilidade dos preços.

No passado, um setor de Tecnologia da Informação (TI), por exemplo, era visto como um centro de custos que não adicionava valor às companhias. Sendo assim, o melhor que um administrador poderia fazer era reduzir os custos de Tl. Obviamente que este cenário mudou. Hoje, as empresas percebem que a Arquitetura da Informação confere uma vantagem competitiva às empresas. As empresas que apresentam o melhor desempenho vão além do foco exclusivo na redução de custos dos serviços empresariais. Ao organizarem de forma estruturada as informações para traduzi-las em conhecimento, conseguem ampliar $o$ mercado consumidor $e$ consequentemente, suas margens de lucro.

Nesse sentido, como as decisões econômicas envolvem mais do que apenas resultados probabilísticos bem definidos, mas são altamente influenciadas pela "confiança" ou pela "crença" do agente econômico, o "grau de confiança" com que os agentes formam tomam suas decisões sobre as variáveis econômicas é altamente dependente da Arquitetura da Informação. 
Tendo em vista que este "grau de confiança", mesmo formado em bases precárias, ainda assim pode ser utilizado para comparar, ordenar, as diversas alternativas de investimento ou de consumo que se colocam ao agente econômico, quanto melhor a Arquitetura da Informação, menor será a incerteza relacionada às decisões dos agentes.

Por fim, como demostrado neste artigo, o comportamento do consumidor depende do custo marginal da pesquisa, da função de distribuição dos preços na economia e do peso do bem pesquisado em seu orçamento. Na decisão de pesquisa, o consumidor diminui o esforço empregado na pesquisa se o custo marginal aumentar. Caso contrário, ele aumenta o seu esforço na busca pelo menor preço. Assim, de forma geral, quanto menor o custo da informação para o consumidor, menor será o valor esperado do preço do produto adquirido. Com efeito, a informação constitui uma importante plataforma que permite com que haja convergência entre as decisões dos consumidores em direção ao menor preço de mercado. Sendo assim, quanto maior a disponibilidade clara e barata de informação ao consumidor e quanto melhor for a Arquitetura da Informação, maior será a tendência de queda do preço no mercado e melhor tenderá a ser o bem-estar da sociedade.

\section{REFERÊNCIAS}

ARROW, K. Economic welfare and the allocation of resources for invention, in NELSON, R. R. (ED.) The rate and direction of inventive activity: economic and social factors, Princeton: Princeton University Press, 1962

BERNANKE, B. S. Non-Monetary Effects of the Financial Crisis in the Propagation of the Great Depression. The American Economic Review. V. 73, n. 3, p. 257-276,1983

BIGGIERO, L.. Organizations as cognitive systems: what do they process and deliver. Department of Economic Systems and Institutions, 2007. Disponível em <http // mpra.ub.uni - muenchen>. Acesso em 25 jun. 2015

BLACKER, F. Knowledge, knowledge work, and organization: an overview and interpretation. Organization Studies, v. 16, n. 6, p. 16-36, 1995.

Brancheau, J. C.; Wetherbe, J. C. Information Architectures: methods and pratice. Information Processing \& Management, v. 22, n. 6, p. 453-463, 1986. 
CAMARGO, L. S. A; VIDOTTI, S. A. B. G. Arquitetura da Informação para Ambientes Informacionais Digitais. In: ENCONTRO NACIONAL DE PESQUISA EM CIÊNCIA DA INFORMAÇÃO, 9, 2008, São Paulo, Anais... São Paulo: ANCIB, 2008. Disponível em: <http://www.enancib2008.com.br>. Acesso em: 26 jun. 2014.

CHOO, C. W. A organização do conhecimento: como as organizações usam a informação para criar significado, construir conhecimento e tomar decisões. São Paulo: SENAC, 2006

DAVENPORT, T. H. Reengenharia de processos: como inovar na empresa através da tecnologia da informação. 5. ed. Rio de Janeiro: Campus, 1998.

LEVY, Pierre. As tecnologias da inteligência: o futuro do pensamento na era da informática. São Paulo: Editora 34, 1997.

LUCAS, R. E. Some international evidence on output-inflation tradeoffs. American Economic Review. n 63, p. 326-335.1973

LUCAS, R. E. Econometric policy evaluation: a critique. Carnegie-Rochester Conference Series on Public Policy. v.1, p. 19-46.1976

LUCAS, R. E. Asset prices in an Exchange Economy. Econometrica, v. 46, n. 6. p. 1426-1445.1978.

LUCAS, R. E.; SARGENT, T. After keynesian macroeconomics. In: Rational expectations and econometric practice. Minneapolis: University of Minnesota, 1981

MUTH, J. F. Rational expectations and the theory of price movements.

Econometrica, v. 29, n. 3 p.315-335,1961.

NIELSEN, J., TAHIR, M. Home Page: usabilidade. Rio de Janeiro: Campus, 2007.

NONAKA, I.; KONNO, N. The concept of BA: building foundation for knowledge creation. California Management Review, v. 40, n. 3, 1998.

MCGEE, J.; PRUSAK, L. Gerenciamento estratégico da informação. 11. ed. Rio de Janeiro: Campus, 1994.

POLANYI, M. Tacit knowledge. In: PRUSAK, L. (Ed.) Knowledge in organizationsresources for the knowledge economy. Boston: Butterworth-Heinemann, 1997. p. 135-146.

ROSENFELD, L.; MORVILLE, P. Information Architecture for the World Wide Web. 2. ed. Cambridge: O'Reilly, 2002

SARGENT, T. A Note on the Accelerationist Controversy. Journal of Money, Credit and Banking. v. 3 (August): 721-25. 1971

SARGENT, T.; WALLACE, N. Rational Expectations, The Optimal Monetary Instrument and The Optimal Money Supply Rule. Journal of Political Economy. n. 83, p. 241254.1975. 
SARGENT, T. Rational Expectations and The Theory of Monetary Policy. Journal of Monetary Economics. 2, p. 169-183.1976.

STIGLER, G. J. The Economics of Information. The Journal of Political

Economics, vol. 69, n.3, p. 213-25. 1961

STIGLITZ, J. Equilibrium in Product Markets with Imperfect Information. American Economic Review, 69, issue 2, p. 339-45.1979.

TURNER, G.; MINONNE, C. Measuring the effects of knowledge management practices. Electronic Journal of Knowledge Management, v. 8 n. 1, p. 161-170, 2010.

TAKEUCHI, H.; NONAKA, I. Gestão do conhecimento. Porto Alegre: Bookman, 2008

URDANETA, I. P. Gestión de la inteligencia, aprendizaje tecnológico y modernización del trabajo informacional: retos y oportunidades. Caracas: Universidad Simón Bolívar, 1992.

WURMAN, R. S. Ansiedade da informação 2: Um Guia para quem comunica e dá instruções. São Paulo: Cultura, 2005.

Title

Information architecture for an economy of information

\begin{abstract}
:
Introduction: The information is intended as a basic raw material, which depend on the processes for decision or learning in the organizational context. Thus the information instead of constituting a primary assumption about the economy is actually more than that, to the extent that it is desired as well by any other economic agents. Objective: The objective of this study was to identify evidence of the conceptual nature of the heterogeneity of information as an important phenomenon that produces a significant impact on the market balance and the welfare of economic agents. Methodology: The research is characterized as a review of literature in the fields of information science, specifically with respect to information architecture, contrasting with the Economy to establish a parallel about the so-called information economy. Results: The main results indicate that having an Information Architecture that enables the ostensible information, enables easy access to knowledge sought by those who demand, is due to its clarity, connectivity, contextualized content to the level of knowledge of users, enabling organizations to maximize the effectiveness of decisions. Conclusion: With regard to the use of an information architecture within an information economy, it is seen that consumers increase the level of utility as the translated information of cheap, light and easily knowledge reduces the degree of dispersion and price volatility.
\end{abstract}

Keywords: Information Architecture. Economy. Search for Information. Classification. Competitive Advantage. 


\section{Titulo}

Arquitectura de información para una economía de información

\section{Resumen:}

Introducción: La información está pensada como una materia prima básica, que dependen de los procesos de decisión o de aprendizaje en el contexto de la organización. Por lo tanto la información en lugar de constituir una suposición primaria sobre la economía es en realidad más que eso, en la medida que se desea, así por otros agentes económicos. Objetivo: El objetivo de este estudio fue identificar la evidencia de la naturaleza conceptual de la heterogeneidad de la información como un fenómeno importante que produce un impacto significativo en el equilibrio del mercado y el bienestar de los agentes económicos. Metodología: La investigación se caracteriza por ser, estudio de caso cualitativo y la técnica de recolección de datos fue la entrevista semiestructurada, aplicada a los asesores de gestión. Resultados: Los principales resultados indican que el tener una arquitectura de información que permite a la información ostensible, permite un fácil acceso a los conocimientos buscados por aquellos que exigen, es debido a su claridad, la conectividad, contenidos contextualizados con el nivel de conocimiento de los usuarios, lo que permite a las organizaciones maximizar la eficacia de las decisiones. Conclusión: Los principales resultados indican que el tener una arquitectura de información que permite a la información ostensible, permite un fácil acceso a los conocimientos buscados por aquellos que exigen, es debido a su claridad, la conectividad, contenidos contextualizados con el nivel de conocimiento de los usuarios, lo que permite a las organizaciones maximizar la eficacia de las decisiones.

Palabras clave: Arquitectura de la información. Economía. Búsqueda de información. Clasificación. La ventaja competitiva.

Recebido: 12.02 .2016

Aceito: 25.03.2017 